\title{
KEPATUHAN PASIEN RAWAT INAP DIET DIABETES MELLITUS BERDASARKAN TEORI KEPATUHAN NIVEN
}

COMPLIANCE DIET INPATIENT DIABETES MELLITUS BASED ON THEORY COMPLIANCE BY NIVEN

Farida Ilmah, Thinni Nurul Rochmah

Fakultas Kesehatan Masyarakat Universitas Airlangga, Surabaya

E-mail: ilmahfarida@gmail.com

\begin{abstract}
Diabetes Mellitus is one of disease related to nutrition. Diabetes Mellitusinpatient's food waste plate is one of the manifestation of noncompliance to the diet program that have been recommended by health workers. This study analyzed the influence of noncompliance inpatients with Diabetes Mellitus diet in dr. M. Soewandhie Surabaya based on the theory compliance by Niven. This was analytic observasionalstudy with cross sectional design. This study used32 samples. Data were analyzed using linear regression test. The results showed that $64.7 \%$ of respondents who have a good attitude did notcomply to the diet, $85,7 \%$ of respondentswho noncompliance to the diet has very good belief. Meanwhile, 50\% of respondents who di not understand the instruction from nutritionists belonging to noncompliance. Then $85.7 \%$ of respondents felt lack of support from their family classified as noncompliance category. While, $75 \%$ of respondents who feel very good quality interaction with nutritionists belonging to noncompliance respondent. While, 66,7\% respondents who got enough support from nutritioniststned to comply the diet. The study showed that official support (nutritionists) influence the patient compliance $(\rho=0,000)$ with a value of $B=-6$. Counseling to inpatients Diabetes Mellitus diet every daycould change the compliance patients.
\end{abstract}

Keywords: compliancetheory, Diabetes mellitus diet, food waste plate, health worker support, niven

\section{PENDAHULUAN}

Masalah kesehatan akan dipengaruhi oleh pola hidup, pola makan, faktor lingkungan kerja, olah raga dan stres. Salah satu yang menyita perhatian masyarakat akhir-akhir ini adalah penyakit Diabetes Mellitus (DM). Diperkirakan pada tahun 2030 Indonesia akan memiliki penyandang Diabetes Mellitus (DM) sebanyak 21,3 juta jiwa (Depkes, 2013).

Penderita diabetes di Surabaya tertinggi kedua setelah Madiun pada Riskesdas Tahun 2007 yaitu sebesar $2,7 \%$ sudah terdeteksi oleh tenaga medis. Berdasarkan hasil Riskesdas, jumlah penderita Diabetes Mellitus (DM) menurut kelompok umur terbanyak pada kelompok umur 55-64 tahun yang artinya kelompok usia tersebut masih tergolong pada kelompok usia yang produktif. Berdasarkan jenis kelaminnya, perempuan lebih banyak mengalami diabetes daripada laki-laki. Tingkat pendidikan penderita diabetes paling banyak adalah pada penduduk dengan tingkat pendidikan yang sudah tamat Perguruan Tinggi (PT).

Diabetes Mellitus (DM)sangat erat kaitannya dengan pola makanan penderita sehari-hari. Makanan yang dikonsumsi oleh pasien rawat inap Diabetes Mellitus (DM) penting untuk dilakukan pengawasan agar gula darah tetap terkontrol. Pada saat pasien Diabetes Mellitus (DM) sedang di rawat inap, maka penyelenggara makanan bagi penderita Diabetes Mellitus (DM) berkaitannya dengan instalasi gizi, karena instalasi gizi merupakan penanggungjawab penyelenggaraan makanan bagi pasien rawat inap.

Makanan yang disajikan oleh instalasi gizi merupakan makanan terbaik untuk mengontrol gula darah pasien rawat inap diet Diabetes Mellitus (DM).Pelayanan gizi rumah sakit dinilai berdasarkan tiga indikator capaian yaitu ketepatan waktu 
pemberian makanan kepada pasien; sisa makananyang tidak termakan oleh pasien; dan tidak adanya kejadian kesalahan pemberian diet.

Instalasi gizi RSUD dr. Mohamad Soewandhie Suarabaya belum mencapai standar pelayanan minimal sesuai dengan standar yang telah ditetapkan departemen kesehatan, namun telah mencapai target sesuai dengan Peraturan Walikota Suarabaya Nomor 50 tahun 2012. Tingginya sisa makanan menunjukkan banyaknya biaya yang terbuang yang mengakibatkan anggaran gizi yang kurang efisien dan merugikan pasien (Djamaluddin, et al., 2005). Sisa makanan yang terlalu banyak juga menyebabkan kurangnya asupan makan pasien sehingga terjadi kekurangan intake gizi esensial yang dapat mempengaruhi status gizi pasien selama melakukan perawatan dirumah sakit.

Diabetes Mellitus memiliki hubungan yang sangat erat dengan makanan, baik dari jumlah makanan, jenis makanan maupun jam makannya. Hasil pengambilan data awal menunjukkan bahwa sisa makanan pasien rawat inap diet DM RSUD dr. Mohamad Soewandhie Surabaya berdasarkan jam makanan (pagi, siang dan sore) secara keseluruhan jauh dari target yang telah ditetapkan dalam sebesar $\leq 35 \%$. Penelitian ini bertujuan untuk menganalisis pengaruh keyakinan, sikap, pemahaman terhadap instruksi, dukungan keluarga, dukungan petugas dan kualitas interkasi terhadap kepatuhan (ditunjukkan dengan pengukuran sisa makanan) pasien rawat inap diet Diabetes Mellitus (DM) di RSUD dr. M. Soewandhie Surabaya.

\section{PUSTAKA}

Kepatuhan secara umum didefinisikan sebagai tingkatan perilaku seseorang yang mendapatkan pengobatan, mengikuti diet, dan melaksanakan gaya hidup sesuai dengan rekomendasi pemberi pelayanan kesehatan (WHO, 2003). Salah satu wujud kepatuhan pasien adalah dengan cara mengikuti anjuran diet yang disarankan oleh ahli gizi. Ahli gizi rumah sakit memberikan rekomendasi atau saran terkait dengan diet yangdianjurkan sesuai dengan penyakit yang diderita pasien tersebut.Instalasi gizi rumah sakit bertanggung jawab menyediakan makanan yang dapat mendukung proses penyembuhan pasien selama dirawat inap.

Sisa makanan adalah salah satu wujud ketidakpatuhan pasien terhadap saran atau rekomendasi dari ahli gizi. Akibat yang ditimbulkan dari ketidakpatuhan diet tersebut tentu sangat merugikan bagi kesehatan pasien tersebut serta merugikan pihak rumah sakit. Menurut Niven (2002) ketidakpatuhan pasien dipengaruhi oleh empat faktor yaitu keyakinan, sikap dan kepribadian, pemahaman terhadap instruksi, isolasi sosial dan keluarga dan kualitas terhadap instruksi.

Keyakinan, sikap, dan kepribadian muncul berdasarkan pengetahuan dan persepsi pada diri sendiri. Pasien yang tidak patuh adalah orang yang lebih mudah mengalami depresi, ansietas, sangat memperhatikan kesehatannya, memiliki kekuatan ego yang lebih lemah dan yang kehidupan sosialnya lebih memusatkan perhatian kapada dirinya sendiri (Niven, 2002). Ciri kepribadian diatas menyebabkan 
seseorang cenderung tidak patuh dari program pengobatan.

Terdapat dua faktor yang mendasari keyakinan seseorang yaitu kerentanan dan keparahan (Niven, 2002). Kerentanan tentang keyakinan individu apakah dirinya menderita sakit. Keyakinan tehadap keparahan yaitu pikiran individi terhadap seberapa berat penyakit yang dideritanya.

Pasien akan patuh menjalan sesuai dengan yang diperintakan kepadanya apabila pasien paham terhadap instruksi yang diperintahkan. Pasien yang tidak paham terhadap instruksi yang diberikan kepadanya maka tidak dapat mematuhi instruksi tersebut dengan baik. Penyebab ketidakpahaman dapat disebabkan oleh tenaga kesehatan sebagai komunikator, pasien sebagai penerima pesan dan karakteristik pesan.

Karakteristik komunikator yaitu meliputi kemampuan tenaga kesehatan dalam menyampaikan pesan, dipengaruhi oleh beberapa faktor yaitu penampilan, kemampuan persuasif komunikator, cara menyampaian pesan, serta daya tarik komunikan. Karakteristik pasien sebagai penerima pesan dipengaruhi oleh kemampuan pasien dalam menagkap informasi yang telah disampaikan oleh komunikator. Karakteristik pesan meliputi kemudahan pesan diterima oleh pasien. Instruksi yang terlalu panjang dan banyak akan sulit dihafal oleh pasien menyebabkan pasien cenderung tidak patuh. Kemampuan melakukan komunikasi secara efektif dengan pasien ditentukan oleh kepribadaian seseorang (Niven, 2002).

Niven (2002) pun menegaskan bahwa derajat seseorang terisolasi dari pendampingan orang lain, isolasi sosial, secara negatif berhubungan dengan kepatuhan. Berdasarkan teori tersebut maka sebesar apapun dukungan yang diberikan kepada pasien, peluang ketidakpatuhan pasien dalam pengobatan akan tetap terjadi apabila pasien merasa terisolasi. Keluarga dapat menjadi faktor yang sangat berpengaruh dalam menentukan keyakinan dan nilai kesehatan dan nilai kesehatan individu serta juga dapat menentukan program pengobatan yang dapat mereka terima.

Keluarga merupakan pihak yang paling dekat dengan pasien. Keluarga menjadi salah satu kunci seseorang berperilaku. Peran keluarga sangat penting dalam memberikan dukungan dan motivasi kepada pasien sehingga pasien patuh dalam menjalani terapi. Dukungan emosional seperti memberikan perhatian, mengingatkan jadwal pengobatan, ataupun menemani pasien saat berobatdapat meningkatkan kepatuhan pada pasien (Niven, 2002).

Kualitas interaksi antara profesional kesehatan dan pasien merupakan bagian yang penting dalam menentukan derajat kepatuhan (Niven, 2002). Terdapat hubungan yang kuat antara kepuasan konsultasi dengan derajat kepatuhan pada pasien. Kualitas interkasi dipengaruhi oleh empat hal yaitu lama, arah, frekuensi serta isi pesan dalam interkasi tersebut (Niven, 2002).

\section{METODE}

Penelitian analitik observasional ini menggunakan rancang bangun penelitian cross sectional. Populasi pada penelitian ini adalah semua pasien rawat inap diet Diabetes Mellitus di RSUD dr. 
Mohamad Soewandhie Surabaya pada bulan Juni 2015. Sampel penelitian ini adalah pasien rawat inap RSUD dr. Mohamad Soewandhie Surabaya yang telah ditetapkan oleh instalasi gizi mendapatkan diet DM, diet yang diberikan secara oral dan bukan termasuk kedalam diet cair. Responden penelitian merupakan pasien yang bukan berasal dari ruang ICU dan bersalin, jugaminimal telah dirawat inap selama 1 hari.

Usia responden lebih dari 15 tahun. Semua responden tidak mengalami gangguan kejiwaan dan memiliki kesadaran dan kemampuan berkomunikasi dengan baik. Sebelum diwawancara pasien diminta mengisi surat persetujuan (informed consent) bersedia menjadi responden dalam penelitian. Penentuan besar sampel menggunakan rumus simple random sampling. Jumlah sampel yang akan diteliti adalah sebanyak 32 responden.

Cara pengambilan sampel pada penelitian ini adalah dengan menggunakan systematic random sampling karena populasi pada penelitian ini bersifat dinamis. Lokasi penelitian ini adalah RSUD dr. Mohamad Soewandhie Surabaya. Penelitian dilakukan pada bulan Mei-Agustus 2015. Instrumen pengumpulan data pada penelitian berupa kuesioner dan lembar observasi sisa makanan. Kuesioner yang digunakan dalam penelitian telah dilakukan uji validitas dan reliabilitas.

Pengukuran kepatuhan pasien diperoleh melalui pengukuran sisa makanan pada pasien dengan metode penimbangan sebelum dan sesudah makanan disajikan kepada pasien. Jumlah sisa makanan yang tidak dihabiskan oleh pasien dibagi dengan jumlah makanan yang disajikan kepada pasien di kali dengan 100\%. Setiap sampel penelitian diukur sisa makanannya selama dua hari (dua kali jam makan pagi, siang dan malam) kemudian diambil rata-rata. Uji pengaruh pada penelitian ini menggunakan Uji Pengaruh Regresi Linear.

\section{HASIL DAN PEMBAHASAN}

Dukungan keluarga yang dapat diberikan oleh keluarga pasien rawat inap diet diabetes kepada responden yaitu dengan bentuk ketelatenan keluarga dalam menyuruh, mengingatkan pasien menghabiskan makanan dan menyuapi pasien selama dirawat inap. Kualitas interaksi merupakan penilaian responden terhadap kualitas hubungan atau interaksi dengan ahli gizi.Kualitas interkasi dinilai atas empat hal yaitu lama, frekuensi, arah dan isi pesan.Dukungan petugas merupakan variabel yang menilai dukungan yang telah diberikan oleh petugas (ahli gizi) terhadap pasien selama dirawat inap di RSUD dr. M. Soewandhie Surabaya.

Sikap menurut (Niven, 2002) merupakan suatu kebiasaan atau suatu keadaan internal individu berupa keyakinan yang diperoleh dari proses akomodasi dan asimilasi pengetahuan yang didapatkan. Semakin baik sikap individu, maka semakin baik pula ketaatan dalam melaksanakan program kesehatan. Hal tersebut belum tergambarkan dalam penelitian ini, variabel sikap pada penelitian ini belum secara signifikan $(\rho=0,227)$ berpengaruh terhadap kepatuhan pasien diet DM. Pengetahuan merupakan modal awal bagi terbentuknya sikap yang akhirnya akan mengarah 
Tabel 1 Uji Pengaruh Variabel Sikap, Keyakinan, Pemahaman terhadap Instruksi, Dukungan Keluarga, Kualitas Interaksi dan Dukungan Petugas terhadap Kepatuhan Pasien Rawat Inap Diet Diabetes Mellitus di RSUD dr M. Soewandhie Surabaya

\begin{tabular}{|c|c|c|c|c|c|c|c|}
\hline & \multirow{3}{*}{ Variabel } & \multicolumn{4}{|c|}{ Kepatuhan } & \multirow{2}{*}{\multicolumn{2}{|c|}{ Total }} \\
\hline & & \multicolumn{2}{|c|}{ Tidak Patuh } & \multicolumn{2}{|c|}{ Patuh } & & \\
\hline & & $\mathbf{n}$ & $\%$ & $\mathbf{n}$ & $\%$ & $\mathbf{n}$ & $\%$ \\
\hline \multirow{4}{*}{ Sikap } & Tidak Baik & 11 & 64,7 & 6 & 35,3 & 17 & 100,0 \\
\hline & Kurang Baik & 4 & 36,4 & 7 & 63,6 & 11 & 100,0 \\
\hline & Cukup Baik & 0 & 0,0 & 2 & 100,0 & 2 & 100,0 \\
\hline & Sangat Baik & 1 & 50,0 & 1 & 50,0 & 2 & 100,0 \\
\hline \multicolumn{8}{|c|}{ Uji Pengaruh Regresi Linier $\rho=0,227$} \\
\hline \multirow{4}{*}{ Keyakinan } & Tidak Yakin & 8 & 100,0 & 0 & 0,0 & 8 & 100,0 \\
\hline & Kurang Yakin & 1 & 16,7 & 5 & 83,8 & 6 & 100,0 \\
\hline & Cukup Yakin & 1 & 9,1 & 10 & 90,9 & 11 & 100,0 \\
\hline & Sangat Yakin & 6 & 85,7 & 1 & 14,3 & 7 & 100,0 \\
\hline \multicolumn{8}{|c|}{ Uji Pengaruh Regresi Linier $\rho=0,550$} \\
\hline \multirow{5}{*}{$\begin{array}{c}\text { Pemahaman } \\
\text { Terhadap Instruksi }\end{array}$} & Tidak Konseling & 11 & 64,7 & 6 & 35,3 & 17 & 100,0 \\
\hline & Tidak Paham & 1 & 50,0 & 1 & 50,0 & 2 & 100,0 \\
\hline & Kurang Paham & 2 & 40,0 & 3 & 60,0 & 5 & 100,0 \\
\hline & Cukup Paham & 0 & 0 & 5 & 100,0 & 5 & 100,0 \\
\hline & Sangat Paham & 2 & 66,7 & 1 & 33,3 & 3 & 100,0 \\
\hline \multicolumn{8}{|c|}{ Uji Pengaruh Regresi Linier $\rho=0,406$} \\
\hline \multirow{4}{*}{$\begin{array}{c}\text { Dukungan } \\
\text { Keluarga }\end{array}$} & Tidak Mendukung & 1 & 100,0 & 0 & 0,0 & 1 & 100,0 \\
\hline & Kurang Mendukung & 6 & 85,7 & 1 & 14,3 & 7 & 100,0 \\
\hline & Cukup Mendukung & 4 & 26,7 & 11 & 73,3 & 15 & 100,0 \\
\hline & Sangat Mendukung & 5 & 55,6 & 4 & 44,4 & 9 & 100,0 \\
\hline \multicolumn{8}{|c|}{ Uji Pengaruh Regresi Linier $\rho=0,155$} \\
\hline \multirow{5}{*}{ Kualitas Interaksi } & Tidak Konseling & 11 & 64,7 & 6 & 35,3 & 17 & 100,0 \\
\hline & Tidak Baik & 0 & 0,0 & 0 & 0,0 & 0 & 100,0 \\
\hline & Kurang Baik & 0 & 0,0 & 3 & 100,0 & 3 & 100,0 \\
\hline & Cukup Baik & 2 & 25,0 & 6 & 75,0 & 8 & 100,0 \\
\hline & Sangat Baik & 3 & 75,0 & 1 & 25,0 & 4 & 100,0 \\
\hline \multicolumn{8}{|c|}{ Uji Pengaruh Regresi Linier $\rho=0,318$} \\
\hline \multirow{5}{*}{$\begin{array}{c}\text { Dukungan } \\
\text { Petugas }\end{array}$} & Tidak Konseling & 11 & 64,7 & 6 & 35,3 & 17 & 100,0 \\
\hline & Tidak Mendukung & 0 & 0 & 0 & 0 & 0 & 0 \\
\hline & Kurang Mendukung & 1 & 50,0 & 1 & 50,0 & 2 & 100,0 \\
\hline & Cukup Mendukung & 3 & 33,3 & 6 & 66,7 & 9 & 100,0 \\
\hline & Sangat Mendukung & 1 & 25,0 & 3 & 75,0 & 4 & 100,0 \\
\hline \multicolumn{8}{|c|}{ Uji Pengaruh Regresi Linier $\rho=0,000 ; B=-6,621$} \\
\hline
\end{tabular}

pada niat akan melakukan perbuatan atau bertindak (Notoatmodjo, 2007). Berdasarkan pernyataan tersebut maka yang harus dilakukan pertama kali adalah memperbaiki pengetahuan pasien sehingga menumbuhkan keyakinan pada pasien yang akhirnya akan menimbulkan sikap yang baik pada pasien. Hal tersebut penting dilakukan karena berdasarkan pada Tabel 1, lebih dari setengah reponden atau sebanyak 17 orang memiliki sikap yang tidak baik. Menurut Gibsonet al. (1996), sikap adalah perbuatan dan sebagiannya yang berdasarkan pada pendirian, serta keyakinan.

Seseorang dengan keyakinan yang baik akan keberhasilan terapi yang dijalani, maka akan meningkatkan kepatuhan pasien dalam menjalani terapi yang dilakukan. Pada penelitian ini, keyakinan tidak berpengaruh secara statistik $(\rho=0,550)$. Sebanyak 11 orang responden memiliki keyakinan yang cukup baik. Pratita (2012) dalam penelitiannya menyebutkan bahwa terdapat hubungan antara Health Locus of Control terhadap kepatuhan pasien 
DM. Health Locus of Control merupakan salah satu bentuk keyakinan seseorang terhadap peristiwa kesehatannya. Dalam teorinya menyebutkan bahwa seseorang yakin bahwa kesehatannya dapat dipengaruhi oleh kontrol dirinya sendiri (kontrol internal) atau keyakinan bahwa kesehatnnya dipengaruhi oleh kontrol dari lingkungan (kontrol eksternal) yaitu salah satunya keluarga maupun tenaga kesehatan.

Salah satu upaya untuk meningkatkan kepatuhan pasien terhadap pengobatannya saat ini adalah dengan melakukan konseling pasien (Ramadona, 2011). Dasar pemaham yang baik adalah komunikasi, komunikasi yang baik antar ahli gizi dengan pasien akan meningkat pemahaman pasien terhadap pengobatan atau terapi yang sedang dijalani.Sebanyak 17 orang responden mengaku bahwa tidak pernah diberikan konseling gizi selama dirawat di rumah sakit.

Pasien tidak dapat mematuhi instruksi jika salah paham dengan instruksi yang diberikan, sehingga pengetahuan ataupun pemahaman pasien tentang diet akan mempengaruhi kepatuhan pasien tersebut dalam sikapnya menghabiskan makanan. Pengaruh pemahaman terhadap instruksi dalam penelitian ini tidak dapat dibuktikan $(\rho=0,406)$. Sebanyak 11 orang responden yang tidak diberikan konseling tidak patuh terhadap diet yang telah dianjurkan. Sebanyak lima orang responden yang menilai cukup paham dengan instruksi yang diberikan oleh ahli gizi, tergolong responden yang patuh.

Menurut Smet (1994), salah satu strategi untuk meningkatkan kepatuhan adalah pemberian informasi, pemberian informasi yang jelas pada pasien dan keluarga mengenai penyakit yang dideritanya serta cara pengobatannya. Dalam hal ini pemberian informasi yang jelas tentang pentingnya menghabiskan makanan yang telah disediakan oleh rumah sakit, sehingga pasien dapat memahami dengan baik tujuan menghabiskan makanan yang telah disediakan dan akhirnya patuh terhadap anjuran dietnya.

Menurut Efendi (2009), dukungan keluarga sangat berperan terhadap kepatuhan yaitu pada penderita yang didukung oleh keluarga akan memiliki percaya diri dan motivasi untuk sembuh. Seseorang dengan dukungan yang tinggi memungkinakan lebih berhasil menghadapi dan menjalankan program diet dibanding dengan yang tidak memiliki dukungan. Dukungan yang dimiliki oleh seseorang dapat mengurai stres dan tekanan yang dihadapi pasien Diabates Mellitus. Tekanan pada pasien rawat inap penyakit Diabates Mellitus tidak hanya pada lingkungan rumah sakit saja, melainkan juga terhadap kompleksitas penyakitnya.

Sebuah keluarga dapat menjadi salah satu faktor yang sangat berpengaruh dalam menuntukan nilai kesehatan individu serta dapat menentukan tindakan yang tepat (Niven, 2002). Smet (1994) mengatakan bahwa salah satu faktor yang mempengaruhi kepatuhan berobat pasien adalah dukungan keluarga, peran keluarga penting untuk mendukung kepatuhan pasien. Pada penelitian ini, menunjukkan bahwa tidak ada pengaruh yang signifikan $(\rho=0,155)$ antar dukungan keluarga terhadap kepatuhan pasien dalam menjalani diet.Menurut Green (1999), dukungan keluarga merupakan salah satu faktor 
penguat yang dapat memengaruhi seseorang untuk melakukan perilaku kesehatan.

Pasien yang memiliki dukungan keluarga yang baik akan mempunyai perasaan yang nyaman yang dapat meningkatkan motivasi mereka untuk patuh terhadap anjuran diet yang telah ditentukan oleh ahli gizi sehingga pasien dapat menurunkan sisa makanan. Sebanyak 11 orang responden atau $73,3 \%$ responden yang merasakan mendapatkan dukungan yang cukup termasuk dalam responden yang patuh. Sebanyak satu responden yang merasa tidak mendapatkan dukungan dari keluarganya tergolong dalam pasien yang tidak patuh.

Smet (1994) berpendapat bahwa untuk meminimalkan dampak stresorakibat kejenuhan pasien terhadappengobatan memerlukan dukunganemosi dari pihak keluarga yang mencakup ungkapan empati,perhatian, dan kepedulian terhadap keadaan pasien. Adanya dukungantersebut meyakini bahwa dirinyadiurus, diperhatikan, dan disayangi.Friedman (2003) berpendapat bahwa kesediaan keluarga dalammembantu anggota keluarga lainyang sedang sakit akanmemberikan dampak pada kesehatan fisik dan mental yanglebih baik.

Dukungan keluarga adalah bagian penting dalam manajemen diabetes, karena anggota keluarga dapat ikut serta dalam banyak aspek aktivitas wajib perawatan kesehatan pasien DM (Yusra, 2011). Salah satu hal yang dapat dilakukan untuk mengatasi penderita diabetes yang melanggar diet adalah dengan cara keluarga yang memberikan dukungan secara emosi (Kartika, 2008). Dukungan emosi yang diberikan oleh keluarga kepada pasien sangat mempengaruhi proses penyembuhan lewat pemberian perhatian, rasa dicintai, dihargai dapat menjadi dukungan yang besar untuk patuh dalam menjalankan diet.

Salah satu penyebab tidak berpengaruhnya dukungan keluarga adalah pasien yang rawat inap mengalami gangguan pengecap (rasa pahit pada mulut) dan berkurangnya nafsu makan sehingga meskipun mayoritas responden mendapatkan dukungan yang cukup, namun kondisi tubuhnya tidak mendukung untuk menghabiskan makanan yang telah disediakan oleh rumah sakit. Peran keluarga sangat penting untuk mendorong pasien agar mau menghabiskan makanannya dengan cara menyuapi sedikit demi sedikit, dengan begitu makanan tidak akan banyak yang tersisa.

Pasien rawat inap dan keluarganya harus secara terus menerus diingatkan tentang manfaat diet yang diberikan untuk pengobatannya dan pengaruhnya terhadap kondisi kesehatannya saat ini. Keluarga pasien juga diberikan pemahaman tentang pemberian makanan dari luar yang tidak dapat dijamin kebaikannya untuk kondisi pasien, sehingga keluarga tidak salah memberikan dukungan kepada pasien.

Berdasarkan hasil penelitian, kualitas interaksi tidak berpengaruh terhadap kepatuhan pasien diet Diabates Mellitus karena $\rho>\alpha(0,05)$. Hal tersebut bisa disebabkan karena responden yang menilai bahwa kualitas interaksinya baik dengan petugas, namun masih menyisakan makanan dalam jumlah yang banyak. Kegiatan penyuluhan kepada pasien merupakan salah satu upaya yang dapat dilakukan oleh instalasi gizi untuk mengatasi masalah sisa 
makanan pada pasien (Murniati, 2008). Sebanyak 17 orang responden tidak dapat dimintai penilaiannya terhadap kualitas interaksi antara dirinya dan ahli gizi, karena tidak pernah diberikan konseling oleh ahli gizi.

Interaksi antara petugas kesehatan dan pasien akan menimbulkan pemahaman terhadap kepentingan pengobatan apabila dalam setiap konsultasi yang dilakukan, petugas kesehatan memberikan perhatian yang penuh kepada pasien, walaupun waktu konsultasi itu sangat pendek (Niven, 2002). Proses konsultasi yang pendek tidak akan menjadi tidak produktif apabila diberi perhatian untuk meningkatkan kualitas interaksi. Berdasarkan pernyataan Niven (2002) tersebut, maka waktu bukan penentu kualitas interaksi itu baik, bisa saja dengan hal lain seperti keramahan, perhatian dan empati petugas seperti penyataan Moehyi (1992) yaitu sikap yang ramah dan penuh perhatian akan memberikan perasaan aman dan keyamanan batin. Tidak hanya dengan keramahan petugas, kualitas interaksi juga dapat diberikan dengan melakukan komunikasi yang baik, sehingga pasien merasa memiliki kedekatan dengan petugas kesehatan. Komunikasi sangat penting dalam melakukan pelayanan gizi kepada pasien, kesediaan dalam memberikan penjelasan, menawarkan alternatif yang dapat membantu pasien dalam memenuhi kebutuhannya dan petugas yang tanggap terhadap kebutuhan pasien (Wahyuningsih, 2009).

Dukungan petugas kesehatan merupakan motivasi dan dorongan dari petugas kesehatan. Berdasarkan PGRS (2013), salah satu tugas dietisien adalah melakukan penyuluhan, motivasi dan konseling gizi kepada pasien dan keluarga pasien. Petugas kesehatan dapat mempengaruhi perilaku penderita dengan cara menyampaikan antusias mereka terhadap tindakan tertentu dari penderita, dan secara terus menerus memberikan dukungan positif (motivasi) bagi penderita yang telah mampu beradaptasi dengan program pengobatannya (Yusra, 2011). Sebanyak 17 orang responden atau sebsear $53,1 \%$ responden tidak mendapatkan konseling selama dirawat di rumah sakit, hal tersebut menyebabkan tidak dapat dilakukan penilaian terhadap dukungan yang diberikan oleh petugas kesehatan (ahli gizi).

Penelitian oleh Jinet al. (2012) berpendapat bahwa dukungan sosial berpengaruh positif terhadap kesehatan psikologis, kesejahteraan fisik, dan kualitas hidup seseorang. Dukungan sosial antara lain dukungan yang bukan berasal dari keluarga. Menurut Niven (2002), dukungan sosial didapatkan melalui jaringan sosial yang terdiri dari anggota-anggota yang dapat menceritakan keluh kesah dan nasehat. Pasien yang sedang dirawat di rumah sakit akan merasakan terisolasi dari lingkungan luar, sehingga dukungan yang paling mungkin adalah dukungan yang berasal dari keluarga dan petugas kesehatan (ahli gizi).

Dukungan petugas (ahli gizi) merupakan salah satu bentuk perhatian dan dorongan yang diberikan oleh orang lain terhadap pasien yang sedang sedang mengalami sakit. Dorongan yang dapat diberikan dalam penelitian ini adalah dorongan keluarga pasien dan dorongan petugas kesehatan (ahli gizi) untuk menghabiskan dan mengonsumsi makanan yang telah disediakan oleh rumah sakit. 
Berdasarkan hasil perhitungan statistik, dukungan petugas memiliki nilai signifikan yang $\rho(0,000)<\alpha$ $(0,05)$, sehingga disimpulkan bahwa dukungan petugas berpengaruh terhadap kepatuhan pasien diet $D M$ dengan $B=-6,621$ yang artinya semakin baik dukungan petugas (ahli gizi) kepada pasien maka akan semakin baik kepatuhan pasien atau semakin sedikit sisa makanan pada pasien rawat inap diet DM.

Dukungan seseorang terhadap pasien yang sedang sakit memberikan motivasi untuk segera sembuh dan dapat beraktivitas kembali. Rasa mendapatkan dukungan dari pihak luar akan membuat pasien merasa diperhatikan, oleh karena itu, petugas kesehatan turut memiliki peran yang nyata dalam memberikan dorongan dan dukungan kepada pasien, sehingga pasien mentaati diet yang telah ditetapkan.

\section{SIMPULAN}

Hasil penelitian menunjukkan bahwa variabel yang berpengaruh yaitu dukungan petugas, sedangkan variabel sikap, keyakinan, pemahaman terhdap instruksi, kualitas interkasi dan dukungan keluarga tidak berpengaruh. Sikap dan keyakinan tidak berpengaruh terhadap kepatuhan pasien karena beberapa faktor salah satunya adalah pengetahuan responden, karena pengetahuan merupakan salah satu pembentuk keyakinan dan sikap yang baik pada seseoarang. Lebih dari setengah responden yang tidak mendapatkan konseling gizi tidak dapat dimintai penilaiannya terhadap variabel pemahaman terhadap instruksi dan kualitas inetraksi. Dukungan keluarga secara teori berpengaruh terhadap kepatuhan, namun pada penelitian ini tidak berpengaruh, kemungkinan disebabkan karena penentu sikap seseorang lebih besar karena dirinya sendiri, bukan dari orang lain atau keluarganya.

Saran yang dapat diberikan yaitu ahli gizi memberikan konseling gizi setiap hari pada pasien rawat inap diet Diabetes Mellitus, jika hal tersebut dirasa kurang dapat dilakukan karena keterbatasan tenaga manusia, maka dapat dilakukan dengan memberlakukan kalimat perintah atau instruksi kepada pasien untuk menghabiskan makanan oleh petugas pengirim makanan agar pasien menghabiskan makanannya. Ahli gizi selain memberikan konseling kepada pasien, konseling sebaiknya dilakukan kepada keluarga pasien agar keluarga pasien tidak salah dalam memberikan dukungannya.

\section{DAFTAR PUSTAKA}

Depkes. 2013. Diabetes Penyebab Kematian Nomor 6 Di Dunia.http://www.depkes.go.id/article/view/23 83/diabetes-melitus-penyebab-kematiannomor-6-di-dunia-kemenkes-tawarkan-solusicerdik-melalui-posbindu.html (sitasi 17 Januari 2015).

Dewi, M., Nursiswati dan Ridwan. 2009. Hubungan Dukungan Keluarga Dengan Kepatuhan Pasien TBC Dalam Menjalani Pengobatan Obat Anti Tuberkulosis di Tiga Puskesmas, Kabupaten Sumedang. Jurnal Kesehatan Masyarakat 10(9): 60-75.

Djamaluddin M., Endy P. P., dan Ira P. 2005. Analisis Zat Gizi Dan Biaya Sisa Makanan Pada Pasien Dengan Makanan Biasa. Jurnal Gizi Klinik Indonesia 1(3): 108-112.

Efendi, dan Makhfudli. 2009. Keperawatan Kesehatan Komunitas Teori dan Prkatik dalam Keperawatan. Salemba Medika. Jakarta.

Friedman, M. M., 1988. Keperawatan Keluarga: Teori dan Praktek. Penerbit Buku Kedokteran EGC. Jakarta.

Gibsons, J. L., John M. I., dan James, H. D. 1996. Organization: Behavior, Structure, Processes, 7th ed, Irwin, Boston. 
Green. L. W., dan Kreuter, M. W. 1999. Helath Promoting Planning an Educational and Environmental Approach, 2nd Edition. Mountain View: Mayfield Publishing Company.

Jin, O. C., Dong, H. C., Dong J. C., dan Min, Y. C. 2012. Assessment of Factors Associated with the Quality of Life in Korean Type 2 Diabetic Patients. Internal Medicine 52: 179-185.

Kartika, I. K., dan Nida H. 2008. Dinamika Emosi Kepatuhan Diet pada Pasien Diabetes Mellitus. Jurnal Penelitian Psikologi 1(13):1120.lib.ugm.ac.id/digitasi/upload/2732_MU.111 10019.pdf.(Sitasi 24 Maret 2015)

Moehyi, S. 1992. Pengaturan Makanan dan Diit Untuk Penyembuhan Penyakit. Cetakan Keempat. PT Gramedia Pustaka Utama. Jakarta.

Murniati, M. 2008. Analisis Pengaruh Manajemen Pelayanan Gizi Terhadap Sisa Makanan Biasa Pasien Rawat Inap di Rumah Sakit Umum Haji Surabaya. Skripsi. Fakultas Kesehatan Masyarakat Universitas Airlangga. Surabaya.

National Health Service (NHS). 2005. Managing Food Waste in the NHS. Department of Health. NHS Estates.

Nida, K. 2011. Faktor-Faktor yang Berhubungan Dengan Sisa Makanan Pasien Rawat Inap di Ruamh Sakit Jiwa Sambang Lihum. Skripsi. Program Studi Gizi Sekolah Tinggi Kesehatan Husada Borneo. Banjarbaru.

Niven, N. 2002. Psikologi Kesehatan Pengantar Untuk Perawat \& Profesional Kesehatan Lain. Penerbit Buku Kedokteran EGC. Jakarta.
Notoatmodjo S. 2007. Promosi Kesehatan dan IImu Perilaku. Rineka Cipta. Jakarta.

Pedoman Pelayanan Gizi Rumah Sakit (PGRS) 2013. Kementrian Kesehatan Republik Indonesia. Jakarta.

Pratita, N. D. 2012. Hubungan Dukungan Pasangan dan Health Locus of Control Dengan Kepatuhan Dalam Mnejalani Proses Pengobatan pada Penderita Diabetes Mellitus Tipe-2. Jurnal IImiah Mahasiswa Universitas Surabaya 1(1).

Ramadona, A. 2011. Pengaruh Konseling Obat Terhadap Kepatuhan Pasien Diabetes Mellitus Tipe 2 di Poli Klinik Khusus Rumah Sakit Umum Pusat dr. M. Djamil Padang. Tesis. Universitas Andalas. Padang.

Smet, B. 1994. Psikologi Kesehatan. Penerbit Buku Kedokteran EGC. Jakarta.

Undang-Undang Republik Indonesia Nomor 44. 2009. Rumah Sakit. 28 Oktober 2009. Lembaran Negara Republik Indonesia Tahun 2009 Nomor 153. Jakarta.

Wahyuningsih, K. 2009. Faktor yang Mempengaruhi Sisa Makanan Penderita Diit Diabetes Mellitus di Rumah Sakit Darmo Surabaya. Skripsi. Fakultas Kesehatan Masyarakat Universitas Airlangga. Surabaya.

World Health Organization. 2003. Adherence LongTerm Therapies. USA.

Yusra, A. 2011. Hubungan antara Dukungan Keluarga dengan Kualitas Hidup Pasien Diabetes Mellitus Tipe 2 di Poliklinik Penyakit dalam RSUP Fatmawati Jakarta. Tesis. Fakultas Kesehatan Masyarakat Universitas Indonesia. Jakarta. 